\title{
Low-Pressure Radiofrequency Cold Plasma for Disinfection of Gutta-Per- cha Cones
}

\author{
M Asnaashari ${ }^{1}$, A Meyari², R Hajrezai ${ }^{3}$, P Paymanpour ${ }^{* 4}$, N Behrooz $^{2}$
}

1- Professor, Laser Application in Medical Sciences Research Center, Shahid Beheshti University of Medical

Sciences, Tehran, Iran.

2- Postgraduate Student, Department of Restorative and Cosmetic Dentistry,Dental Faculty, Tehran Medical

Sciences, Islamic Azad University, Tehran, Iran

3- Assistant Professor, Orthodontics Dept, Dental Faculty, Tehran Medical Sciences, Islamic Azad University,

Tehran, Iran

4- Assistant Professor, Department of Endodontics, Shahid Beheshti University of Medical Sciences, Tehran, Iran.

5- Postgraduate Student, Department of Restorative and Cosmetic Dentistry, Dental Faculty, Tehran Medical Sciences, Islamic Azad University, Tehran, Iran

\begin{tabular}{l}
\hline ARTICLE INFO \\
\hline Article History \\
Received: Nov 2019 \\
Accepted: Dec 2019 \\
ePublished: Feb 2020
\end{tabular}

Corresponding author: P Paymanpour, Assistant professor, Department of Endodontics, Shahid Beheshti Unversity of Medical Sciences Email: Payam_Paymanpour@yahoo.com

\begin{abstract}
Background and Aim: Different methods have been proposed for rapid disinfection of gutta-percha (GP) cones. This study aimed to assess the efficacy of low-pressure radiofrequency cold plasma (LRFCP) in disinfection of GP cones compared to three chemical disinfectants.

Materials and Methods: Seventy GP cones were allocated to seven groups of 10 each. All samples were initially sterilized with ethylene oxide (EO) and subsequently inoculated with Staphylococcus aureus (S. aureus), except for the negative control group $(n=10)$. In the experimental groups $(n=50)$, samples were subjected to oneminute chemical disinfection [5.25\% sodium hypochlorite $(\mathrm{NaOCl}), 2 \%$ chlorhexidine (CHX), and 10\% Deconex ${ }^{\circledR} 53$ PLUS) or LRFCP (30 seconds or one minute). The effectiveness of disinfection was evaluated by counting the colony-forming units (CFUs). Data were analyzed using Kruskal-Wallis test $(\mathrm{P}=0.05)$.

Result: All experimental groups effectively eliminated S. aureus. LRFCP and $5.25 \%$ $\mathrm{NaOCl}$ were the most effective agents in disinfection of GP cones. In addition, $2 \%$ CHX was significantly weaker than the other agents $(\mathrm{P}<0.05)$. Although Deconex ${ }^{\circledR}$ 53 PLUS was less potent than LRFCP groups and $\mathrm{NaOCl}(\mathrm{P}>0.05)$, it showed higher antibacterial activity than $2 \% \mathrm{CHX}(\mathrm{P}>0.05)$.

Conclusion: LRFCP can be assumed as a noninvasive and efficient method for disinfection of GP cones.

Keywords: Disinfection, Gutta-Percha, Cold Plasma, Staphylococcus aureus
\end{abstract}

\section{J Res Dent Maxillofac Sci 2020;5(2):14-20}

\section{Introduction:}

The main objective of endodontic obturation is to hinder the recontamination of a prepared root canal space by the oral microbiota. ${ }^{(1)}$ Pulp and periapical pathoses are directly related to the presence of microorganisms. ${ }^{(2,3)}$ Thus, elimination or massive reduction in the number of exogenous or endogenous microorganisms throughout endodontic treatment should be regarded as the fundamental concept to achieve a successful outcome. ${ }^{(4,5)}$
Gutta-percha (GP) cones are commonly used for root canal filling. They might become contaminated by pathogens during handling and storage in clinical use. Hence, many authors have recommended chair-side disinfection of GP cones before use. ${ }^{(5-8)}$ Since GP has thermoplastic characteristics, it cannot undergo heat sterilization. However, different chemical agents have been proposed for rapid chemical disinfection of GP cones. ${ }^{(5,9)}$ Some physical changes have been reported after such procedures. ${ }^{(10-12)}$ 
Plasma, a partially or fully ionized gas often referred to as the fourth state of matter, features quasineutrality and collective behavior. ${ }^{(13)}$ The sterilizing effect of plasma was reported by Menashi for the first time in 1968. ${ }^{(14)}$ Efficient inactivation of different types of pathogens, including vegetative bacteria, bacterial endospores, fungi, viruses, prions, and endotoxins, has been reported for non-thermal/cold plasmas. ${ }^{(15)}$ To date, there has been no research on the efficacy of cold plasma for decontamination of GP cones. Therefore, this study aimed to compare lowpressure radiofrequency cold plasma (LRFCP) with rapid chemical sterilization techniques [5.25\% sodium hypochlorite $(\mathrm{NaOCl}), 2 \%$ chlorhexidine $(\mathrm{CHX})$, and $10 \%$ Deconex ${ }^{\circledR} 53$ PLUS] for decontamination of GP cones inoculated with Staphylococcus aureus (S. aureus).

\section{Materials and Methods:}

To evaluate LRFCP for disinfection of GP cones, 70 \#80 GP cones were sterilized with ethylene oxide (EO). In addition to positive $(n=10)$ and negative control $(n=10)$ groups, five groups of 10 samples each were designated to receive one of the following protocols: LRFCP $(60 \mathrm{~W}$, 30 seconds), LRFCP (60W, one minute), $\mathrm{NaOCl}$ (5.25\%, one minute), CHX ( $2 \%$, one minute), and Deconex ${ }^{\circledR} 53$ PLUS (10\%, one minute). ). Negative controls were used for assessment of the efficacy of the initial EO sterilization process. Positive controls were used for obtaining the baseline colony-forming unit (CFU) count as well as confirmation of bacterial growth on the samples throughout the study. S. aureus (ATCC 25923) was streak-cultured from the frozen stock on a nutrient agar plate (Merck, Germany) and incubated at $37^{\circ} \mathrm{C}$ for 24 hours. A bacterial concentration compatible with $0.5 \mathrm{McF}$ arland standard was prepared from freshly cultured bacterial colonies and diluted with $0.9 \%$ sodium chloride $(\mathrm{NaCl})$ to obtain the final microbial suspensions at the concentration of $1-2 \times 10^{6} \mathrm{CFUs} / \mathrm{ml}$.

Contamination of GP cones in the experimental and positive control groups:

Every five samples, regardless of being experimental or control, were inserted into one sterile Eppendorf tube containing one $\mathrm{ml}$ of the aforementioned microbial suspension and left for 30 minutes to promote surface adsorption. Thus, in total, 12 Eppendorf tubes were used for bacterial inoculation of positive and experimental groups.
These contaminated GP cones were transferred to petri dishes that had been matted with two layers of sterile filter paper and placed in a dry heat sterilizer for 30 minutes at $37^{\circ} \mathrm{C}$ until they were dry. Each sample was then placed in a sterile Eppendorf tube filled with one $\mathrm{ml}$ of sterile nutrient broth and incubated at $37^{\circ} \mathrm{C}$ for 48 hours. A table of random numbers was used for the allocation of samples to the groups.

\section{Chemical protocols:}

The agents used for chemical disinfection were $5.25 \% \mathrm{NaOCl}$ (Cerkamed, Poland), 2\% CHX (Coltene, Switzerland), and 10\% Deconex ${ }^{\circledR} 53$ PLUS (Borer Chemie AG, Switzerland). Each inoculated sample was immersed in one of these agents for one minute. Before returning each GP to a new Eppendorf tube containing $1 \mathrm{ml}$ sterile nutrient broth, sterile saline bath was used for washing the chemical residues.

\section{Cold plasma sterilization:}

An RF plasma reactor (13.56 MHz, 60W), a research reactor designed by the School of Advanced Technologies in Medicine at Shahid Beheshti University of Medical Sciences, Tehran, Iran, was used for either 30 -second or one-minute exposure of allocated samples. The volume and the pressure of the chamber were $1000 \mathrm{~cm} 3$ and 0.1 mbar equal to 10 Pascals (Pa), respectively. Each sample was then immediately transferred to a new Eppendorf tube containing $1 \mathrm{ml}$ of sterile nutrient broth.

After 10 minutes of immersion, all tubes were vortexed and the broth was subjected to 2-fold serial dilution; $100 \mu 1$ of each dilution was transferred to a nutrient agar plate and incubated at $37^{\circ} \mathrm{C}$ for 48 hours. Thereafter, CFUs were counted for each GP cone; microbial detection limit was determined to be three CFUs. Since the distribution of the data was not normal, reduction in the number of colonies was analyzed with Kruskal-Wallis test using SPSS software (version 22, SPSS Inc., Chicago, IL, USA). The level of significance was set at 0.05 . Multiple comparisons were made using Dunn's multiple comparison test. 


\section{Results:}

Kruskal-Wallis test was used for statistical analysis $(\alpha=0.05)$. After the first 48 hours, all positive controls showed positive results whereas negative controls demonstrated no microbial growth, inferring effective initial EO sterilization. All methods showed significant antibacterial activity against $\mathrm{S}$. aureus in comparison with the positive control group $(\mathrm{P}<0.001)$. LRFCP and $5.25 \% \mathrm{NaOCl}$ were significantly more effective than 2\% CHX (P-values for 30-second LRFCP, one-minute LRFCP groups, and $\mathrm{NaOCl}$ were $0.003,0.001$, and 0.003 , respectively). The difference between LRFCP and $5.25 \% \mathrm{NaOCl}$ was not significant $(\mathrm{P}>0.05)$.
Deconex ${ }^{\circledR} 53$ PLUS was insignificantly more potent than $2 \% \mathrm{CHX}$ and less effective than LRFCP and 5.25\% NaOCl ( $\mathrm{P}>0.05)$. Moreover, $2 \%$ CHX was significantly weaker compared to the other three experimental groups $(\mathrm{P}<0.05)$. Although Deconex ${ }^{\circledR} 53$ PLUS was less potent than LRFCP groups and $\mathrm{NaOCl}(\mathrm{P}>0.05)$, it showed higher antibacterial activity than $2 \%$ CHX $(\mathrm{P}>0.05)$. Table 1 shows the data related to different study groups.

Figure 1 demonstrates the mean rank values for the experimental groups.

Table 1. Colony-forming unit (CFU) counts for the experimental and positive control

\begin{tabular}{|c|c|c|c|c|c|}
\hline & \multicolumn{5}{|c|}{ groups $(n=10)$} \\
\hline Groups & Minimum & Maximum & Mean & SD & Sterilization (\%) \\
\hline LRFCP (30 seconds) & 0 & 1 & 0.2 & 0.42 & 80 \\
\hline LRFCP (one minute) & 0 & 1 & 0.1 & 0.31 & 90 \\
\hline Deconex 53PLUS & 0 & 2 & 0.8 & 0.79 & 40 \\
\hline $5.25 \% \mathrm{NaOCl}$ & 0 & 1 & 0.2 & 0.42 & 80 \\
\hline $2 \%$ CHX & 0 & 3 & 1.7 & 0.94 & 10 \\
\hline Positive Control & 21 & 224 & 62.3 & 64.90 & $\mathrm{~N} / \mathrm{A}$ \\
\hline
\end{tabular}

$C H X=$ chlorhexidine, $L R F C P=$ low-pressure radiofrequency cold plasma, $\mathrm{NaOCl= \text {sodium }}$ hypochlorite, $S D=$ standard deviation, $N / A=$ not applicable

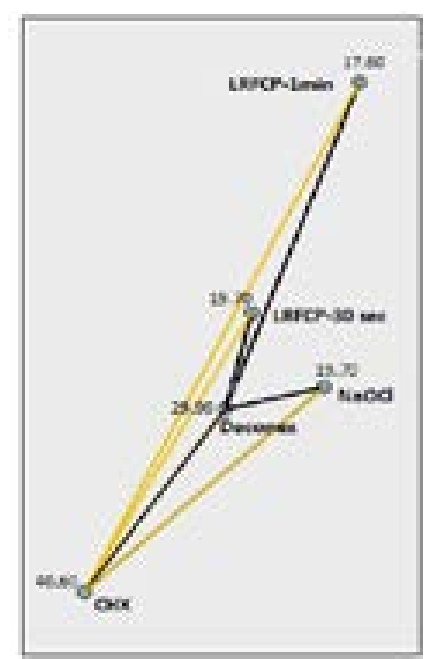

Figure 1. Mean rank values for the experimental groups. $\mathrm{CHX}=$ chlorhexidine, $\mathrm{LRFCP}=$ low-pressure radiofrequency cold plasma, $\mathrm{NaOCl}=$ sodium hypochlorite. 


\section{Discussion:}

The goal of this study was to compare the antibacterial effectiveness of LRFCP with that of rapid chemical technique using $5.25 \% \mathrm{NaOCl}$, $2 \%$ CHX, and 10\% Deconex ${ }^{\circledR} 53$ PLUS for decontamination of GP cones inoculated with $\mathrm{S}$. aureus.

The ultimate goal in endodontic treatment is to reduce the bacterial load as much as possible to provide an environment conducive to healing. ${ }^{(16)}$ In this regard, aseptic practices, including sterilization of armamentarium and decontamination of the operative field and materials, are crucial. GP cones are very popular as an obturating material in endodontics. They offer thermoplasticity, tissue tolerance, dimensional stability, and radiopacity. Moreover, they can be readily removed in case of endodontic retreatments. Since the placement of GP is the final step of obturation of a prepared root canal, the clinical condition of GP cones is a matter of concern. Despite the inherent antibacterial properties of GP, which have been mainly attributed to its zinc oxide component, ${ }^{(4,17,18)}$ many studies have shown the presence of bacteria on commercial GP cones in sealed boxes or shortly after exposure to the clinical environment. ${ }^{(8,19-21)}$ Because GP is heat-labile, a wide array of chemical disinfectants have been proposed to disinfect GP cones before root canal obturation. ${ }^{(5-8,19,21-24)}$ However, some physical changes in GP cones after such procedures seem to be unavoidable. ${ }^{(10-12,25)}$ Gamma irradiation, a nonchemical approach for heat-sensitive materials, also poses some problems including time-dependent physical and chemical damage. ${ }^{(26,27)}$ Plasma, a partially ionized gas, has several anti-pathogenic properties. ${ }^{(15,28-36)}$ Inactivation of microorganisms by plasma is strongly related to generated electrons and ions. Because of the high flux and penetration depth of electrons, they induce the formation of reactive oxygen species (ROS) and strong oxidants in contact with water. Similarly, the chemical effect of ions can generate highly reactive oxidants. Moreover, ion bombardment can cause cell membrane damage by mechanical impact. ${ }^{(28)}$

In this study, RF plasma was used for disinfection of GP cones because these plasmas are characterized by displacement current, inferring that charges only oscillate within the electric field without flowing to the electrodes; this allows the electrodes to be placed outside the low-pressure compartment, resulting in reliability, reproducibility, and increased lifetime of the reactor. ${ }^{(37)}$ LRFCPs have been used for processing of fibers, biomedical and microfluid devices, polyacrylate/ silica nanocomposites, and decontamination of endodontic files. ${ }^{(38-43)}$ In the present study, we used S. aureus for inoculation of GP cones. The rationale behind this was the fact that the main contaminating bacteria present on GP cones are vegetative bacterial cells (Staphylococcus spp.) rather than resistant spores. ${ }^{(21,25)}$ Thus, the use of arbitrary resistant or spore-forming flora as target microorganisms may not be highly clinically relevant. ${ }^{(9)}$ Staphylococci are the normal flora of the skin and mucous membranes with the ability of extracellular polysaccharide synthesis, initiating biofilm formation. ${ }^{(4)}$ It has been proposed that the biofilm formed on overextended GPs might be related to refractory periapical pathoses. ${ }^{(45,46)}$ Based on the finding of this study, LRFCP treatments were equally efficacious to $5.25 \%$ $\mathrm{NaOCl}$. However, immersion of GP cones in $5.25 \% \mathrm{NaOCl}$, known as rapid sterilization technique initially proposed by Senia et al, ${ }^{(5)}$ has been frequently suggested as an efficient, reliable, convenient, and inexpensive method of GP decontamination. ${ }^{(5-7,21,23)}$ There are some concerns regarding chemical deterioration of GP and chloride precipitation, ${ }^{(25,47,48)}$ its aggressiveness towards periapical tissues, ${ }^{(21,23,47)}$ as well as difficulties with fresh preparation of the solution and its chemical stability. ${ }^{(4)}$ While different methods have been recommended for elimination of residual crystals forming, ${ }^{(47,50)}$ they increase the time needed for clinical use, negatively affecting the reported efficiency for the original technique. In contrast, RFCP used in this study has no toxic residual effect and reduced turnover time. ${ }^{(51,52)}$ In $\mathrm{CP}$, the temperature of electrons is considerably higher than that of heavy particles, and the electron density is normally below $10^{19} \mathrm{~m}^{-3}$. As heavy particles determine overall temperature, a CP simultaneously serves the purpose of high reactivity using energetic electrons and low temperature due to low-energy heavy particles. ${ }^{(53)}$ In this study, the pressure of the chamber was first lowered to further promote electron acceleration rather than heavy particle collisions. ${ }^{(54)}$ Secondly, 
RF was used to guarantee electron stimulation instead of ion oscillation. ${ }^{(5)}$ Thus, elevated temperature can be readily ruled out as a major phenomenon in bacterial inactivation. Concern over RFCP is that the complex surface structure such as pits, cracks, and grooves can shield pathogens from reactive species and thus impede microbial inactivation. ${ }^{(35,55,56)}$ According to the finding of the present study, this is not the case for GP cones as they do not have complex geometry where microorganisms can hide; therefore, LRFCP was as effective as $\mathrm{NaOCl}$.

Although some studies have shown a single slope exponential microbial decay, reflecting equal exposure of a homogenous culture to identical conditions or predominance of elevated temperature as major inactivation effect for plasmas, $(32,33,55)$ the present study revealed multi-slope microbial inactivation characteristics and biphasic curves. This finding is in line with most studies on plasma decontamination. ${ }^{(34-36)}$

\section{Conclusion:}

Within the limitations of this study, LRFCP can be considered as a valuable tool for disinfection of GP cones.

\section{References:}

1. Mozayeni MA, Zadeh YM, Paymanpour P, Ashraf $\mathrm{H}$, Mozayani M. Evaluation of push-out bond strength of AH26 sealer using MTAD and combination of $\mathrm{NaOCl}$ and EDTA as final irrigation. Dent Res J (Isfahan). 2013 May;10(3):359-63.

2. Stashenko P. Etiology and pathogenesis of pulpitis and apical periodontitis. In: Ørstavik D, Pitt Ford TR. Essential endodontology. Blackwell Science, Oxford, 1998:42-67.

3. Mousavi SA, Ghoddusi J, Mohtasham N, Shahnaseri S, Paymanpour P, Kinoshita J. Human pulp response to direct pulp capping and miniature pulpotomy with MTA after application of topical dexamethasone: arandomized clinical trial. Iran Endod J. 2016 Spring;11(2):85-90.

4. Attin T, Zirkel C, Pelz K. Antibacterial Properties of Electron Beam-Sterilized Gutta-Percha Cones. J Endod. 2001 Mar;27(3):172-4.

5. Senia ES, Marraro RV, Mitchell JL, Lewis AG, Thomas L. Rapid sterilization of gutta-percha cones with $5.25 \%$ sodium hypochlorite. J Endod. 1975 Apr;1(4):136-40.

6. Ozalp N, Okte Z, Ozcelik B. The rapid sterilization of gutta-percha cones with sodium hypochlorite and glutaraldehyde. J Endod. 2006 Dec;32(12):1202-4.

7. Siqueira JF Jr, da Silva CH, Cerqueira M das D, Lopes HP, de Uzeda M. Effectiveness of four chemical solutions in eliminating Bacillus subtilis spores on gutta-percha cones. Endod Dent Traumatol. 1998 Jun;14(3):124-6.

8. Montgomery S. Chemical decontamination of gutta-percha cones with polyvinylpyrrolidone-iodine. Oral Surg Oral Med Oral Pathol. 1971;31(2):258-266. 9. Frank RJ, Pelleu GB Jr. Glutaraldehyde decontamination of gutta-percha cones. J Endod. 1983 Sep;9(9):368-70.

10. Möller B,Örstavik D. Influence of antiseptic storage solutions on physical properties of endodontic guttapercha points. Eur J Oral Sci. 1985 Apr;93(2):15861.

11. Valois CR, Silva LP, Azevedo RB. Effects of $2 \%$ chlorhexidine and $5.25 \%$ sodium hypochlorite on gutta-percha cones studied by atomic force microscopy. Int Endod J. 2005 Jul;38(7):425-9.

12. Lee MY, Park DS. An experimental study of the effect of the various antiseptic storage solutions on physical properties of gutta-percha cone. Res Dent Endod. 1991;16(1):209-15.

13. Hippler R, Kersten H, Schmidt M, Schoenbach KH. Low temperature plasmas. Berlin: Wiley, 2008:787.

14. Menashi WP.Treatment of surfaces. US Patent 3 383 163, May 14, 1968.

15. Kelly-Wintenberg K, Hodge A, Montie T, Deleanu L, Sherman D, Reece Roth J, et al. Use of a one atmosphere uniform glow discharge plasma to kill a broad spectrum of microorganisms. J Vac Sci Technol A. 1999;17(4):1539-44.

16. Naseri M, Paymanpour P, Kangarloo A, Haddadpur S, Dianat O, Ketabi MA. Influence of motion pattern on apical transportation and centering ability of WaveOne single-file technique in curved root canals. Dent Res J (Isfahan). 2016Jan-Feb;13(1):13-17.

17. Moorer WR, Genet JM. Antibacterial activity of gutta-percha cones attributed to the zinc oxide component. Oral Surg Oral Med Oral Pathol. 1982 May;53(5):508-17.

18. Weiger R, Manncke B, Löst C. Antibacterial effect of gutta-percha cones on endodontopathogenic microorganisms. Dtsch Zahnärztl Z. 1993;48:658-60.

19. da Motta PG, de Figueiredo CB, Maltos SM, Nicoli JR, Ribeiro Sobrinho AP, Maltos KL, et al. Efficacy of chemical sterilization and storage conditions of gutta-percha cones. Int Endod J. 2001 Sep;34(6):435-9.

20. Linke HA, Chohayeb AA. Effective surface sterilization of gutta-percha points. Oral Surg Oral Med Oral Pathol Oral Radiol. 1983 Jan;55(1):73-7.

21. Gomes BP, Vianna ME, Matsumoto CU, Rossi 
Vde P, Zaia AA, Ferraz CC, et al. Disinfection of gutta-percha cones with chlorhexidine and sodium hypochlorite. Oral Surg Oral Med Oral Pathol Oral Radiol Endod. 2005 Oct;100(4):512-7.

22. Royal MJ, Williamson AE, Drake DR. Comparison of $5.25 \%$ sodium hypochlorite, MTAD, and $2 \%$ chlorhexidine in the rapid disinfection of polycaprolactone-based root canal filling material. J Endod. 2007 Jan;33(1):42-4.

23. Cardoso CL, Kotaka CR, Redmerski R, Guilhermetti M, Queiroz AF. Rapid decontamination of gutta-percha cones with sodium hypochlorite. J Endod. 1999 Jul;25(7):498-501.

24. Gomes BP, Ferraz CC, Vianna ME, Berber VB, Teixeira FB, Souza-Filho FJ. In vitro antimicrobial activity of several concentrations of sodium hypochlorite and chlorhexidine gluconate in the elimination of Enterococcus faecalis. Int Endod J. 2001 Sep;34(6):4248.

25. Pang NS, Jung IY, Bae KS, Baek SH, Lee WC, Kum KY. Effects of short-term chemical disinfection of gutta-percha cones: identification of affected microbes and alterations in surface texture and physical properties. J Endod. 2007 May;33(5):594-8.

26. Sauer WL, Weaver KD, Beals NB. Fatigue performance of ultra-high-molecular-weight polyethylene: effect of gamma radiation sterilization. Biomaterials. 1996 Oct;17(20):1929-35.

27. Goldman M, Lee M, Gronsky R, Pruitt L. Oxidation of ultrahigh molecular weight polyethylene characterized by Fourier Transform Infrared Spectrometry. J Biomed Mater Res. 1997 Oct;37(1):43-50.

28. Fridman A. Plasma Chemistry. Cambridge University Press, 2008:848-913.

29. Raballand V, Benedikt J, Wunderlich J, Von Keudell A. Inactivation of Bacillus atrophaeus and of Aspergillus niger using beams of argon ions, of oxygen molecules and of oxygen atoms. J Phys D Appl Phys. 2008 May;41(11):115207.

30. Rossi F, Kylián O, Rauscher H, Hasiwa M, Gilliland D. Low pressure plasma discharges for the sterilization and decontamination of surfaces. New J Phys. 2009 Nov;11(11): 115017.

31. Rauscher H, Kylián O, Benedikt J, von Keudell A, Rossi F. Elimination of biological contaminations from surfaces by plasma discharges: chemical sputtering. Chemphyschem. 2010 May 17;11(7):1382-9.

32. Deng S, Ruan R, Mok CK, Huang G, Lin X, Chen P. Inactivation of Escherichia coli on almonds using nonthermal plasma. J Food Sci. 2007 Mar;72(2):M62-6.

33. Laroussi M, Leipold F. Evaluation of the roles of reactive species, heat, and UV radiation in the inactivation of bacterial cells by air plasmas at atmospheric pressure. Int J Mass Spectr. 2004;233(1-3):81-6.

34. Boudam MK, Moisan M, Saoudi B, Popovici C,
Gherardi N, Massines F. Bacterial spore inactivation by atmospheric-pressure plasmas in the presence or absence of UV photons as obtained with the same gas mixture. J Phys D Appl Phys. 2006;39(16):3494.

35. Hertwig C, Reineke K, Ehlbeck J, Knorr D, Schlüter O. Decontamination of whole black pepper using different cold atmospheric pressure plasma applications. Food Control. 2015;55:221-9.

36. Hury S, Vidal DR, Desor F, Pelletier J, Lagarde T. A parametric study of the destruction efficiency of Bacillus spores in low pressure oxygen-based plasmas. Lett Appl Microbiol. 1998 Jun;26(6):417-21.

37. Roth JR. Industrial Plasma Engineering: Volume 1: Principles. CRC Press, 1995:538.

38. Mejia M, Marin J, Restrepo G, Pulgarin C, Mielczarski E, Mielczarski J, et al. Self-cleaning modified TiO2-cotton pretreated by UVC-light $(185 \mathrm{~nm})$ and RF-plasma in vacuum and also under atmospheric pressure. Appl Catal B Environ. 2009 Sep;91(12):481-8.

39. Martin IT, Dressen B, Boggs M, Liu Y, Henry CS, Fisher ER. Plasma Modification of PDMS Microfluidic Devices for Control of Electroosmotic Flow. Plasma Process Polym. 2007;4(4):414-24.

40. Gentsch R, Pippig F, Schmidt S, Cernoch P, Polleux J, Börner HG. Single-step electrospinning to bioactive polymer nanofibers. Macromolecules. 2011;44(3):453-61.

41. Slaney AM, Wright VA, Meloncelli PJ, Harris KD, West LJ, Lowary TL, et al. Biocompatible carbohydrate-functionalized stainless steel surfaces: a new method for passivating biomedical implants. ACS Appl Mater Interfaces. 2011 May;3(5):1601-12.

42. Hsu SH, Chang YL, Tu YC, Tsai CM, Su WF. Omniphobic low moisture permeation transparent polyacrylate/silica nanocomposite. ACS Appl Mater Interfaces. 2013 Apr 24;5(8):2991-8.

43. Whittaker A, Graham E, Baxter R, Jones A, Richardson P, Meek G, et al. Plasma cleaning of dental instruments. JHosp Infect. 2004;56(1):37-41.

44. Gill SR, Fouts DE, Archer GL, Mongodin EF, Deboy RT, Ravel J, et al. Insights on evolution of virulence and resistance from the complete genome analysis of an early methicillin-resistant Staphylococcus aureus strain and a biofilm-producing methicillin-resistant Staphylococcus epidermidis strain. J Bacteriol. 2005 Apr;187(7):2426-38.

45. Noiri Y, Ehara A, Kawahara T, Takemura N, Ebisu S. Participation of bacterial biofilms in refractory and chronic periapical periodontitis. J Endod. 2002 Oct;28(10):679-83.

46. Takemura N, Noiri Y, Ehara A, Kawahara T, Noguchi N, Ebisu S. Single species biofilm-forming ability of root canal isolates on gutta-percha points. Eur J Oral Sci. 2004 Dec;112(6):523-9. 
47. Short RD, Dorn SO, Kuttler S. The crystallization of sodium hypochlorite on gutta-percha cones after the rapid-sterilization technique: an SEM study.J Endod. 2003 Oct;29(10):670-3.

48. Goldberg F, Massone E, Pruskin E, Zmener O. SEM study of surface architecture of gutta-percha cones. Endod Dent Traumatol. 1991 Feb;7(1):15-8.

49. Grossman LI, Meiman BW. Solution of pulp tissue by chemical agents. J Am Dent Assoc. 1941Feb;28(2):223-5.

50. Cohen S, Burns R. Pathways of the pulp. 7th ed: St. Louis: CV Mosby, 1994:509.

51. Ayliffe G. Minimal Access Therapy Decontamination Working Group. Decontamination of minimally invasive surgical endoscopes and accessories. J Hosp Infect. 2000 Sept;45(4):263-77.

52. Montie TC, Kelly-Wintenberg K, Roth JR. An overview of research using the one atmosphere uniform glow discharge plasma (OAUGDP) for sterilization of surfaces and materials. IEEE Trans Plasma Sci. 2000;28(1):41-50.

53. Tendero C, Tixier C, Tristant P, Desmaison J, Leprince P. Atmospheric pressure plasmas: A review. Spectrochim Acta B. 2006;61(1):2-30.

54. Cobine JD. Gaseous conductors: theory and engineering applications. New York, NY: Dover, 1958:218-225.

55. Butscher D, Van Loon H, Waskow A, Rudolf von Rohr P, Schuppler M. Plasma inactivation of microorganisms on sprout seeds in a dielectric barrier discharge. Int J Food Microbiol. 2016 Dec 5;238:222-32. 56. Schnabel U, Niquet R, Krohmann U, Polak M, Schlüter O, Weltmann K, et al. Decontamination of microbiologically contaminated seeds by microwave driven discharge processed gas. JAgric Sci Appl. 2012;1(4):99-105.

Please cite this paper as: Asnaashari M, Meyari A, Hajrezai R, Paymanpour P, Behrooz N. Low-Pressure Radiofrequency Cold Plasma for Disinfection of Gutta-Percha Cones. J Res Dentomaxillofac Sci. 2020; 5 (2) :14-20 